OPEN ACCESS

Edited by:

Zhanqi Zhao,

Furtwangen University, Germany

Reviewed by:

Zhiyu Xiao,

Sun Yat-sen University, China

Cale Kassel,

University of Nebraska Medical

Center, United States

*Correspondence:

Zhi-Yong Du

duzhiyong88@163.com

Specialty section:

This article was submitted to

Intensive Care Medicine and

Anesthesiology,

a section of the journal

Frontiers in Medicine

Received: 18 November 2021

Accepted: 16 December 2021

Published: 10 January 2022

Citation:

Luo B-W and Du Z-Y (2022) Advances

in Diagnostic Imaging of

Hepatopulmonary Syndrome.

Front. Med. 8:817758.

doi: 10.3389/fmed.2021.817758

\section{Advances in Diagnostic Imaging of Hepatopulmonary Syndrome}

\author{
Bi-Wei Luo and Zhi-Yong Du*
}

Department of Hepatobiliary and Pancreas Surgery, Shenzhen People's Hospital (The Second Clinical Medical College, Jinan University; The First Affiliated Hospital, Southern University of Science and Technology), Shenzhen, China

Hepatopulmonary syndrome (HPS) is a serious pulmonary complication of progressive liver disease that leads to a poor clinical prognosis. Patients with HPS may develop acute respiratory failure, which requires intensive care and therapy. At present, the only effective treatment is liver transplantation; therefore, early diagnosis and timely treatment are of considerable significance. The three main features of HPS are liver disease, oxygenation disorder, and intrapulmonary vascular dilatation (IPVD). Diagnosing HPS is challenging due to the difficulty in detecting the presence or absence of IPVD. As such, imaging examination is very important for detecting IPVD. This paper reviews the imaging methods for diagnosing HPS such as ultrasound, dynamic pulmonary perfusion imaging, pulmonary angiography, and computed tomography.

Keywords: hepatopulmonary syndrome, diagnostic imaging, liver disease, IPVD, pulmonary vasodilation

\section{INTRODUCTION}

When liver disease progresses to a certain stage, it is followed by the onset of pulmonary vasodilation, pulmonary gas exchange disorder, decrease in the arterial oxygen partial pressure, and clinical manifestations, which is called hepatopulmonary syndrome. In 1956, Rydell and Hoffbauer first reported a patient with liver cirrhosis complicated with a pulmonary arteriovenous fistula and described the pathophysiology of hypoxemia (1). In 1977, Kennedy and Knudson first used the term "hepatopulmonary syndrome (HPS)" to describe pulmonary vascular disease secondary to liver cirrhosis and it has been used thereafter (2). Subsequently, Sherlock further elaborated on hepatopulmonary syndrome (3). There is a clear connection between hypoxemia and liver disease. In presence of liver disease, it appears that pulmonary vasodilatation (PV) leads to a mismatch between ventilation/perfusion and diffusing capacity. The diagnostic criteria for HPS: (1) presence of liver disease, (2) evidence of intrapulmonary vascular dilatation (IPVD), which is also the basic pathological change, and (3) a pulmonary bubble arterial oxygen differential pressure $\left[\mathrm{P}[\mathrm{A}-\mathrm{a}] \mathrm{O}_{2}\right.$ gradient] that is $\geq 15 \mathrm{mmHg}$ (or $>20 \mathrm{mmHg}$ if age $\geq 65$ years). The severity of HPS can be classified according to the $\mathrm{PaO}_{2}$ into either mild $\left(\mathrm{PaO}_{2} \geq 80 \mathrm{mmHg}\right)$, moderate $\left(\mathrm{PaO}_{2} 60-79 \mathrm{mmHg}\right)$, severe $\left(\mathrm{PaO}_{2} 50-59 \mathrm{mmHg}\right)$, or very severe $\left(\mathrm{PaO}_{2}<50 \mathrm{mmHg}\right)$ (4). HPS mostly occurs in patients with liver cirrhosis, with an incidence rate of $9.45-42.5 \%$ (5-10). HPS is a serious pulmonary complication of end-stage liver disease. The mortality of patients with HPS is significantly high and the prognosis is poor (10). Early detection and timely treatment may help improve the prognosis. HPS should be considered if there is abnormal pulmonary arterial oxygenation in the presence of liver disease; however, abnormal blood oxygen saturation alone is not enough to diagnose HPS (9). The focus of clinical diagnosis is to identify evidence of PV in patients with chronic liver disease 
complicated with hypoxemia. Therefore, clinical assessment must be combined with the results of imaging examination. This paper presents a comprehensive review of the latest developments in the diagnostic imaging of HPS.

\section{PROGRESS IN ULTRASOUND USE FOR THE DIAGNOSIS OF HPS}

With the onset of HPS, patients have a higher cardiac output and hyperdynamic circulation, resulting in corresponding changes in the cardiac structure. HPS can be indirectly diagnosed by measuring the cardiac structure using cardiac color Doppler ultrasound. Zamirian conducted a cardiac B-ultrasound examination on adult patients with confirmed HPS and found that the left atrial volume (LAV) was increased significantly. In patients with liver cirrhosis, HPS is considered if the measured LAV is $>50 \mathrm{ml}$, and sensitivity and specificity are estimated to be 86.3 and $81.2 \%$, respectively (11). This is mainly due to the right to left shunt in patients with HPS, resulting in increased cardiac output and increased left heart volume (11). A previous study proved that increased LAV can reflect the presence of HPS in patients with liver cirrhosis, and increased systemic blood velocity through the mitral valve can also indirectly indicate the presence of HPS (12). Moreover, Soulaidopoulos found that absolute left ventricular (LV) global longitudinal strain (GLS) values are significantly lower in patients with HPS compared to cirrhotic patients without HPS (13). Furthermore, results from a previous study suggest that systolic pulmonary artery pressure, right ventricle wall width, and early filling (E) and late filling (A) ratio (E/A ratio) can predict IPVD (14). The right ventricular diastolic dysfunction rate also increases significantly in patients with liver cirrhosis, especially in patients with HPS (15). As HPS can cause changes in the cardiac structure, cardiac ultrasound measurement can help in making an indirect diagnosis. This method is simple and convenient and especially suitable for preliminary screening of HPS in primary medical units (16).

\section{PROGRESS IN CONTRAST ENHANCED ECHOCARDIOGRAPHY (CEE) FOR THE DIAGNOSIS OF HPS}

The hand vibration method is used to produce microbubbles with a diameter $\leq 90 \mu \mathrm{m}$ in normal saline, followed by injection into an upper limb vein of the patient. If the patient does not have a right to left shunt, the microbubbles will be captured and absorbed by the pulmonary capillary bed, and will not be able to reach the left cardiac system. Conversely, if the subject has pulmonary capillary dilation or a right to left shunt, the microbubbles will reach the left cardiac system, and can be detected in the left heart by ultrasonic examination. This method is called contrast-enhanced echocardiography. At present, the commonly used methods are contrast-enhanced transthoracic echocardiography (CTTE) and contrast-enhanced transesophageal echocardiography (CTEE). CTTE is a simple, non-invasive technique, low cost, and safe. However, CTEE is an invasive procedure that is relatively complex and entails a high cost. However, CTEE can provide excellent image quality, has a higher sensitivity that can improve the detection rate, and is significantly better for the diagnosis of PV compared to CTTE (17-19).

Some researchers have attempted to increase the sensitivity of CEE by changing the operation mode. For example, CEE examination in a standing position is observed to be better than that in a supine position, which may be due to the expansion of the pulmonary basal blood vessels and increased blood flow because of gravity $(20,21)$. Moreover, 3D CEE can obtain more $2 \mathrm{D}$ images and provide more data for analysis. CEE has a higher sensitivity and can better diagnose HPS compared to CTEE (22). A previous study estimated the erythrocyte pulmonary transit time (PTT) by detecting the time from the right atrium to the left atrium by CEE. It was found that PTT may be a useful parameter for evaluating arterial oxygenation in patients with chronic liver disease with early HPS (23). Another study also revealed that contrast enhanced transcranial Doppler was more sensitive for the detection of IPVD with a low false positive rate (24).

$\mathrm{CEE}$ is the most commonly used diagnostic imaging method for PV and the right to left shunt. It is simple, convenient, minimally invasive, and highly sensitive. At present, it is the gold standard for diagnosis. CEE also has some limitations. As an example, since many patients with liver cirrhosis may have normal blood gas content, the positive detection rate for such patients is only $40 \%$ by CEE. Further, other diseases of the lung can also lead to abnormal gas exchange. Therefore, using $\mathrm{CEE}$, positive findings in the lungs alone are not enough for the diagnosis of HPS.

\section{PROGRESS IN TECHNETIUM 99M-LABELED MACROAGGREGATED ALBUMIN (TC-MMA) DYNAMIC LUNG PERFUSION SCAN FOR THE DIAGNOSIS OF HPS}

Dynamic pulmonary perfusion imaging is one of the common methods for diagnosing pulmonary vascular abnormalities in HPS. Technetium labeled human serum albumin polymer particle is a large albumin particle with a diameter $>20 \mu \mathrm{m}$. A certain amount of Tc-MMA is injected into the peripheral vein of the patient at one time. The whole process of the radionuclide passing through cardiopulmonary vessels is recorded in the anterior and posterior positions by the $\gamma$ camera during cardiovascular dynamic imaging. After $5 \mathrm{~min}$, the posterior and anterior positions are taken for whole-body imaging, and the computer is used for synchronous data collection and imaging. The whole-body and bilateral lung radioactivity counts are calculated by the region of interest method, and the right to left shunt ratio of Tc-MMA is also calculated. Tc-MMA persists in the capillary beds with a diameter of $8-15 \mu \mathrm{m}$, and when the pulmonary capillaries show abnormal dilation and arteriovenous communication, Tc-MMA can pass through the abnormally dilated pulmonary vessels. This can help in obtaining extrapulmonary organ imaging and determining the intrapulmonary partial flow, which can help to diagnose patients 
with HPS $(25,26)$. Zhao et al. evaluated the sensitivity, specificity, and accuracy of the brain and systemic uptake of 99mTc-MAA in IPVD, and found that the whole-body uptake was better than simple brain uptake (27). The overall sensitivity of 99mTc-MAA in the diagnosis of HPS is $18.9 \%$ in all HPS cases, which is relatively low, but it is $66.7 \%$ in severe to very severe cases. Consequently, it can be used in patients with pulmonary disease and severe to very severe HPS (28).

Tc-MAA perfusion lung scan is more sensitive than CEE in detecting an intrapulmonary shunt in children with HPS (29). Some studies have suggested that there is no significant difference between the two in detecting an intrapulmonary shunt in children with HPS (6). In general, the detection sensitivity of 99 mTc-MAA is lower than that of CEE, although its specificity is higher than that of CEE for the diagnosis of HPS. However, the greatest limitation of this imaging examination is that it cannot distinguish between an intracardiac and intrapulmonary shunt, nor can it evaluate cardiac function and pulmonary artery pressure. In addition, it can produce false positive results because non-bound technetium can pass through the vessels with a normal width.

\section{PROGRESS IN PULMONARY ANGIOGRAPHY FOR THE DIAGNOSIS OF HPS}

Pulmonary angiography refers to selective pulmonary angiography carried out by puncture of peripheral blood vessels (usually femoral veins) and insertion of catheters. According to the different angiographic manifestations and pathophysiological characteristics, HPS can be divided into type I and type II (30). In type I, normal or diffuse, small, spider-like branching dilatations can be seen in the early stage. With the progression of dilatation, blotchy or spongy diffuse dilatation can be observed. Type II is relatively rare, showing anatomic arteriovenous malformations similar to spider nevus (31). Pulmonary angiography can directly reveal the dilated blood vessels and can also be used for embolization and other treatments (32). In addition, the determination of PTT by pulmonary angiography is very useful for the diagnosis of HPS, with higher sensitivity compared to the Tc-MAA lung perfusion scan, and may even be used to quantify the degree of intrapulmonary shunting (33).

Pulmonary angiography has not been widely used in clinical settings as it is invasive and expensive. It is mainly used in patients with persistent hypoxemia who have a poor response to inhaled pure oxygen and need intrapulmonary vascular embolization. In some HPS patients, PV is microscopic, and pulmonary angiography may not reveal any abnormality.

\section{ADVANCES IN THE COMPUTED TOMOGRAPHY (CT) DIAGNOSIS OF HPS}

The principal manifestations of chest CT in HPS include thickening and distortion of the lung basal texture, mediumsized nodular or reticular nodular shadows at the bottom of the lung, arteriovenous malformations, cardiac enlargement, and pulmonary artery widening (34). In addition to the number and location of pulmonary arteriovenous malformations, CT can also display the lung parenchyma pattern such as a mosaic pattern, which is characterized by alternating low attenuation areas (pulmonary vessels with reduced diameter) and high attenuation areas (pulmonary vessels with normal diameter). This mosaic pattern of the lung parenchyma is speculated to be associated with HPS and may be a potentially useful marker for the diagnosis of HPS, but still needs to be confirmed by large research studies (34).

High-resolution CT (HRCT) can show the expansion of the subpleural vessels that extend to the pleura, which is helpful for the diagnosis of HPS (35). Chest HRCT can also help in the diagnosis of HPS by calculating the ratio of the pulmonary artery to the bronchial diameter in the basal segment of the right lower lobe (36). Some studies have shown that although the arterial bronchial ratio of the basal segment in patients with liver disease is greater than that in the normal control group, this vasodilation is not serious in patients with HPS (37), and the incidence is low (7). CT cannot adequately distinguish if liver disease is complicated by HPS. For example, in a patient with HPS complicated with emphysema, an intrapulmonary shunt examination by $99 \mathrm{mTc}-\mathrm{MAA}$ showed that the systemic shunt rate was $43 \%$ and there was no vasodilation on chest CT (38). Therefore, more research data are needed to support CT imaging for HPS.

In one study, lung images were obtained by single-photon emission computed tomography and CT. After merging, the images revealed that there were subpleural reticular nodular shadows and/or dilated blood vessels at the bottom of the lung in patients with HPS. This seems to be a characteristic CT manifestation of intrapulmonary arteriovenous communications in the lungs of HPS patients (39).

\section{DISCUSSION}

With the development of HPS in patients with liver disease, there are different degrees of abnormal dilatation of the pulmonary vessels. The rapid and accurate diagnosis of HPS through an imaging examination is particularly important. Routine cardiac B-ultrasound can indirectly diagnose HPS by measuring the changes in the ventricular structure. At present, contrast echocardiography and Tc-MAA dynamic lung perfusion imaging can indirectly indicate the existence of an intrapulmonary right to left shunt. It is the most used examination method in the clinic, with a high sensitivity but low specificity. Pulmonary angiography can directly show the changes in the pulmonary vessels with high sensitivity and specificity, but it is more traumatic, expensive, and limited in application. CT can directly show the morphological changes in the pulmonary vessels, and facilitate the diagnosis of HPS based on specific signs. Although there are still some controversies, it can help in the diagnosis of HPS. With the recent developments in multienergy computed tomography (MECT) diagnostic technology, it has been used in the clinical diagnosis of various diseases 
of the whole body, especially vascular imaging. Researchers have applied MECT in the diagnosis of pulmonary vascular disease because it provides additional information for assessing the pulmonary vascular system (40). MECT provides new avenues for research and may become a new diagnostic method for HPS.

Overall, the progress of research on the diagnostic imaging of HPS has been relatively slow. In the future, there is a need to increase the clinical and basic research on HPS to further deepen the understanding of its pathogenesis and investigate new examination techniques to improve diagnostic efficiency.

\section{REFERENCES}

1. Hoffbauer FW, Rydell R. Multiple pulmonary arteriovenous fistulas in juvenile cirrhosis. Am J Med. (1956) 21:450-60. doi: 10.1016/ 0002-9343(56)90043-2

2. Kennedy TC, Knudson RJ. Exercise-aggravated hypoxemia and orthodeoxia in cirrhosis. Chest. (1977) 72:305-9. doi: 10.1378/chest.72.3.305

3. Sherlock S, Dooley J. Sherlock's Diseases of the Liver and Biliary System. 8th ed. Oxford: Blackwell Scientific (1989). doi: 10.1097/00004836-199008000-00036

4. Raevens S, Geerts A, Devisscher L, Van Vlierberghe H, Van Steenkiste C, Colle I. Recent advances in the approach to hepatopulmonary syndrome and portopulmonary hypertension. Acta Gastro Enterol Belgica. (2021) 84:95-9. doi: $10.51821 / 84.1 .200$

5. Cárdenas Ramírez B, Padilla-Machaca PM, Mantilla Cruzatti O, Rivera Romaní J, Rondón Leyva C, Chaman Ortiz JC. [Hepatopulmonar syndrome and liver transplantation: experience in the transplantation department of the Guillermo Almenara Irigoyen National Hospital - EsSalud]. Rev Gastroenterol Peru. (2018) 38:242-7.

6. Ceza MR, Garcia E, Anselmi CE, Epifanio M, Melere MU, Ferreira CT, et al. Prevalence and characteristics of hepatopulmonary syndrome in children with cirrhosis in southern Brazil. Eur J Gastroenterol Hepatol. (2019) 31:10-5. doi: 10.1097/MEG.0000000000001207

7. Folador L, Torres FS, Zampieri JF, Machado BC, Knorst MM, Gazzana MB. Hepatopulmonary syndrome has low prevalence of pulmonary vascular abnormalities on chest computed tomography. PLoS ONE. (2019) 14:e0223805. doi: 10.1371/journal.pone.0223805

8. Khiangte B, Kothakota SR, Sasidharan M, Kareem H, Joshi S, Kumar VV, et al. Prevalence and determinants of hepatopulmonary syndrome in decompensated chronic liver disease. Indian J Gastroenterol. (2020) 39:362-9. doi: 10.1007/s12664-020-01052-9

9. Rose SCP, Cunha DV, Medeiros SBC, Trevizoli JE, Carneiro MV, Freitas WM, et al. Correlation between hepatopulmonary syndrome and oxygen saturation pulse oximetry in cirrhotic patients. Rev Assoc Med Brasil. (1992) (2020) 66:1577-82. doi: 10.1590/1806-9282.66.11.1577

10. Han SK, Kim MY, Kang SH, Suk KT, Baik SK. Hepatopulmonary syndrome is related to the development of acute-on-chronic liver failure and poor prognosis in cirrhotic patients. Hepatol Int. (2021) 15:1207-14. doi: 10.1007/s12072-021-10226-2

11. Zamirian M, Aslani A, Sharifkazemi MB. Prediction of intrapulmonary right to left shunt with left atrial size in patients with liver cirrhosis. Eur J Echocardiogr. (2008) 9:1-4. doi: 10.1016/j.euje.2006.10.003

12. Pouriki S, Alexopoulou A, Chrysochoou C, Raftopoulos L, Papatheodoridis G, Stefanadis C, et al. Left ventricle enlargement and increased systolic velocity in the mitral valve are indirect markers of the hepatopulmonary syndrome. Liver Int. (2011) 31:1388-94. doi: 10.1111/j.1478-3231.2011.02591.x

13. Soulaidopoulos S, Vlachou M, Cholongitas E, Giannakoulas G, Panagiotidis T, Drakopoulou M, et al. Assessment of biventricular function in patients with hepatopulmonary syndrome. Int J Cardiovasc Imaging. (2021) 37:2891-900. doi: 10.1007/s10554-021-02260-w

14. Voiosu A, Voiosu T, Stănescu CM, Chirilă L, Băicuş C, Voiosu R. Novel predictors of intrapulmonary vascular dilatations in cirrhosis: extending the role of pulse oximetry and echocardiography. Acta Gastro Enterol Belg. (2013) $76: 241-5$

\section{AUTHOR CONTRIBUTIONS}

B-WL: writing-original draft. Z-YD: writing-review and editing and funding acquisition. All authors contributed to the article and approved the submitted version.

\section{FUNDING}

This work was supported by Shenzhen Key Medical Discipline Construction Fund (No. SZXK015) and Science and Technology Innovation Foundation of Shenzhen (JCYJ20190807144807510).

15. Karabulut A, Iltumur K, Yalcin K, Toprak N. Hepatopulmonary syndrome and right ventricular diastolic functions: an echocardiographic examination. Echocardiography. (2006) 23:271-8. doi: 10.1111/j.1540-8175.2006.00 210.x

16. Alves Pinto R, Rodrigues J, Almeida PB. Echocardiographic diagnosis of hepatopulmonary syndrome: a valuable tool to remember. Intern Emerg Med. (2021) 16:2299-300. doi: 10.1007/s11739-021-02731-x

17. Aller R, Moya JL, Moreira V, Boixeda D, Cano A, Picher J, et al. Diagnosis of hepatopulmonary syndrome with contrast transesophageal echocardiography: advantages over contrast transthoracic echocardiography. Digest Dis Sci. (1999) 44:1243-8. doi: 10.1023/A:1026657114256

18. Fischer CH, Campos O, Fernandes WB, Kondo M, Souza FL, De Andrade $\mathrm{JL}$, et al. Role of contrast-enhanced transesophageal echocardiography for detection of and scoring intrapulmonary vascular dilatation. Echocardiography. (2010) 27:1233-7. doi: 10.1111/j.1540-8175.2010.01228.x

19. Gouvea A, Fischer CH, Arakaki JSO, Mancuso FJ, Brant P, Moisés VA, et al. Value of contrast transesophageal echocardiography in the detection of intrapulmonary vascular dilatations in hepatosplenic schistosomiasis. Arq Brasil Cardiol. (2019) 113:915-22. doi: 10.5935/abc.20190200

20. Lenci I, Alvior A, Manzia TM, Toti L, Neuberger J, Steeds R. Saline contrast echocardiography in patients with hepatopulmonary syndrome awaiting liver transplantation. J Am Soc Echocardiogr. (2009) 22:89-94. doi: 10.1016/j.echo.2008.09.020

21. Sekioka A, Nii M, Fukumoto K, Miyake H, Urushihara N. Hepatopulmonary syndrome revealed via echocardiography in the upright position. Pediatr Int. (2020) 62:646-7. doi: 10.1111/ped.14145

22. Gaber R, Ziada DH, Kotb NA, Abo El-Magd GH, Hamisa M. Detection of hepatopulmonary syndrome in patients with liver cirrhosis using 3D contrast echocardiography. Arab J Gastroenterol. (2012) 13:14-9. doi: 10.1016/j.ajg.2012.03.004

23. Katsuta Y, Honma H, Zhang XJ, Ohsuga M, Komeichi H, Shimizu S, et al. Pulmonary blood transit time and impaired arterial oxygenation in patients with chronic liver disease. J Gastroenterol. (2005) 40:57-63. doi: 10.1007/s00535-004-1495-6

24. Ramírez Moreno JM, Millán Núñez MV, Rodríguez Carrasco M, Ceberino D, Romaskevych-Kryvulya O, Constantino Silva AB, et al. [Detection of an intrapulmonary shunt in patients with liver cirrhosis through contrast-enhanced transcranial Doppler. A study of prevalence, pattern characterization, and diagnostic validity]. Gastroenterol Hepatol. (2015) 38:475-83. doi: 10.1016/j.gastrohep.2015.02.006

25. Fragaki M, Sifaki-Pistolla D, Samonakis DN, Koulentaki M, Koukouraki S, Stathaki M, et al. Screening for hepatopulmonary syndrome in cirrhotic patients using Technetium 99m-macroaggregated Albumin Perfusion Lung Scan (Tc-MAA): diagnostic approach and clinical correlations. J Clin Gastroenterol. (2018) 52:828-34. doi: 10.1097/MCG.0000000000000926

26. Surasi DS, Manapragada P, Bhambhvani P. Lung perfusion imaging in hepatopulmonary syndrome using $(99 \mathrm{~m}) \mathrm{Tc}$ macroaggregated albumin. $J$ Nuclear Cardiol. (2015) 22:586-8. doi: 10.1007/s12350-014-9990-5

27. Zhao H, Tsauo J, Zhang XW, Ma HY, Weng NN, Tang GS, et al. Technetium-99m-labeled macroaggregated albumin lung perfusion scan for diagnosis of hepatopulmonary syndrome: a prospective study comparing brain uptake and whole-body uptake. World J Gastroenterol. (2020) 26:108897. doi: 10.3748/wjg.v26.i10.1088 
28. Grilo I, Pascasio JM, Tirado JL, López-Pardo FJ, Ortega-Ruiz F, Sousa JM, et al. The utility of the macro-aggregated albumin lung perfusion scan in the diagnosis and prognosis of hepatopulmonary syndrome in cirrhotic patients candidates for liver transplantation. Rev Esp Enferm Dig. (2017) 109:335-43. doi: 10.17235/reed.2017.4219/2016

29. El-Shabrawi MH, Omran S, Wageeh S, Isa M, Okasha S, Mohsen NA, et al. $(99 \mathrm{~m})$ Technetium-macroaggregated albumin perfusion lung scan versus contrast enhanced echocardiography in the diagnosis of the hepatopulmonary syndrome in children with chronic liver disease. Eur J Gastroenterol Hepatol. (2010) 22:1006-12. doi: 10.1097/MEG.0b013e328336562e

30. Krowka MJ, Dickson ER, Cortese DA. Hepatopulmonary syndrome. Clinical observations and lack of therapeutic response to somatostatin analogue. Chest. (1993) 104:515-21. doi: 10.1378/chest.104.2.515

31. Krowka MJ, Cortese DA. Hepatopulmonary syndrome. Current concepts in diagnostic and therapeutic considerations. Chest. (1994) 105:1528-37. doi: $10.1378 /$ chest.105.5.1528

32. Ryu JK, Oh JH. Hepatopulmonary syndrome: angiography and therapeutic embolization. Clin Imaging. (2003) 27:97-100. doi: 10.1016/S0899-7071(02)00511-9

33. Zhao $H$, Tsauo J, Zhang $X$, Ma $H$, Weng $N$, Wang $L$, et al. Pulmonary transit time derived from pulmonary angiography for the diagnosis of hepatopulmonary syndrome. Liver Int. (2018) 38:1974-81. doi: 10.1111/liv.13741

34. Gorospe Sarasúa L, Olavarría-Delgado A, Farfán-Leal FE, Pérez-Templado Ladrón de Guevara J. Hepatopulmonary syndrome with large pulmonary arteriovenous malformations: CT findings with emphasis on its association with a mosaic pattern of the lung parenchyma. Rev Esp Enferm Dig. (2017) 109:369.

35. Kumar S, Arora A, Bhatia V. Hepatopulmonary syndrome: a clinicoradiological diagnosis. Indian J Gastroenterol. (2013) 32:209-10. doi: 10.1007/s12664-013-0309-2

36. Köksal D, Kaçar S, Köksal AS, Tüfekçioglu O, Küçükay F, Okten $S$, et al. Evaluation of intrapulmonary vascular dilatations with high-resolution computed thorax tomography in patients with hepatopulmonary syndrome. J Clin Gastroenterol. (2006) 40:77-83. doi: 10.1097/01.mcg.0000190775.57903.86

37. Chen YA, Prabhudesai V, Castel H, Gupta S. CT scan does not differentiate patients with hepatopulmonary syndrome from other patients with liver disease. PLoS ONE. (2016) 11:e0158637. doi: 10.1371/journal.pone.0158637

38. Taniguchi $\mathrm{H}$, Kanbara $\mathrm{K}$, Imanishi $\mathrm{S}$, Abo H, Izumi S. [Case of hepatopulmonary syndrome with no vascular dilation in chest CT]. Nihon Kokyuki Gakkai Zasshi. (2008) 46:466-9.

39. Suga K, Kawakami Y, Iwanaga H, Tokuda O, Matsunaga N. Findings of hepatopulmonary syndrome on breath-hold perfusion SPECT-CT fusion images. Ann Nuclear Med. (2009) 23:413-9. doi: 10.1007/s12149-009-0250-8

40. Rajiah P, Tanabe Y, Partovi S, Moore A. State of the art: utility of multi-energy $\mathrm{CT}$ in the evaluation of pulmonary vasculature. Int J Cardiovasc Imaging. (2019) 35:1509-24. doi: 10.1007/s10554-019-01615-8

Conflict of Interest: The authors declare that the research was conducted in the absence of any commercial or financial relationships that could be construed as a potential conflict of interest.

Publisher's Note: All claims expressed in this article are solely those of the authors and do not necessarily represent those of their affiliated organizations, or those of the publisher, the editors and the reviewers. Any product that may be evaluated in this article, or claim that may be made by its manufacturer, is not guaranteed or endorsed by the publisher.

Copyright (c) 2022 Luo and Du. This is an open-access article distributed under the terms of the Creative Commons Attribution License (CC BY). The use, distribution or reproduction in other forums is permitted, provided the original author(s) and the copyright owner(s) are credited and that the original publication in this journal is cited, in accordance with accepted academic practice. No use, distribution or reproduction is permitted which does not comply with these terms. 